\title{
Combining methods of speech therapy to develop the lexical side of speech in older preschool children with motor alalia
}

\author{
V.N. Zinovieva ${ }^{1 *}$, A.P. Demidova ${ }^{2}$, and A.V. Danilkina ${ }^{3}$ \\ ${ }^{1}$ The Tsiolkovsky Kaluga State University, Kaluga, Russia \\ ${ }^{2}$ The Tsiolkovsky Kaluga State University, Kaluga, Russia \\ ${ }^{3}$ Municipal, budgetary, educational institution "secondary school №22", Kaluga, Russia
}

\begin{abstract}
This article discusses the diagnosis of lexical aspect of speech, that allows to identify disorders of lexical aspect of speech in children with motor alalia at the older preschool age. Based on the data obtained in the course of speech therapy examination, a corrective work on the development of the lexical side of speech is presented and organized with the help of existing methods. Moreover this article presents the results of the work done, which prove the effectiveness of combining methods of speech therapy for the development of lexical aspect of speech in children older preschool with motor alalia.
\end{abstract}

\section{A problem statement}

Speech is a system consisting of a great number of interrelated elements and structures. If one of the elements of this system is disrupted or completely dysfunctional, full-fledged speech development is impossible [1].

One of the most severe speech disorders is motor alalia, in which developmental defects are noted in all categories of speech activity. Among preschool children with language system disorders, alalia occurs in $1 \%$ of children and most of them have a motor form of this systemic speech underdevelopment [2]. It is important to note that the prevalence of alalia increases every year, so the problems of speech development of children suffering from expressive alalia deserve much attention. One of these problems is the study of the development of the lexical aspect of speech in older preschool children with motor alalia.

Vocabulary is of great importance in mastering the native language as a means of communication. It has, forms and transmits knowledge about any objects, phenomena, their qualities and actions. If the lexical category is violated, the child has difficulties with communication, cognitive activity, intellectual, mental and social development [3].

Based on the above, the relevance of the problem of developing the lexical aspect of speech in children with motor alalia at the older preschool age is: 1) in the rapid growth of the level of distribution of the disorder, 2) in the fact that vocabulary defects will slow down and limit the speech and general development of a child.

* Corresponding author: ipcs-profped@yandex.ru 


\subsection{The objective of the work}

To diagnose the level of formation of the lexical category of speech in older preschool children with motor alalia, as well as to identify specific and individual features, we used: 1) methodology for examining the dictionary of I.A. Smirnova; 2) methodology for examining the vocabulary of L.S. Solomakha and N.V. Serebryakova; 3) methodology for examining the emotional vocabulary of I. U. Kondratenko.

During the direct correctional work on the development of the vocabulary of the studied category of children, we used and combined: 1) the adapted method of "Emotions"; 2) the method of forming semantic connections of words; 3) the method of using laptops; 4) the method of cinquain; 5) the method of theatrical activity.

Also, to carry out high-quality work, we used: 1) the concept of learning of the occurrence of alalia by M.B. Grinshpun, M.E. Hvatzeva, A. Kussmaul, N.N. Traugott, V.K. Ordinsky; 2) the concept of learning classifications by A. Libman, R.E. Levina, V.K. Orfinsky, V.A. Kovshikov; 3) the concept of learning non-speech and speech symptoms of motor alalia by L.S. Volkova, V.A. Kovshikov, G.V. Gurova, V. Landau, T.B. Filicheva, G.V. Chircina, E.V. Sobotovich, N.N. Traugott, G.I. Zarenkova.

\section{Materials and the results of the research}

The aim of the study is to research the features of correction of the lexical aspect of speech in older preschool children with motor alalia. To achieve this goal, the following tasks were set:1) conducting a comprehensive survey that allows to identify the level of the dictionary formation, as well as to highlight the features of its development; 2) organization of the correctional speech therapy work, taking into account the pathogenetic principle and the principle of individual approach; 3) providing targeted and systematic speech therapy assistance for the development of the lexical aspect of speech by systematizing, individualizing and combining the methods, techniques and material used; 4) identifying and evaluating the effectiveness of speech therapy work on the development of the lexical category of speech in older preschool children with motor alalia.

In modern speech therapy, which studies all speech mechanisms and defects, there are a number of severe speech disorders. One of the leading among them is alalia. The commonly used definition of alalia is formulated by G.V. Chirkina. She defines this disorder as the absence or systemic underdevelopment of speech in children with normal hearing and primary preserved intelligence [4].

It is also important to note that, despite the fact that there are many classifications in modern speech therapy, the most frequently used classification is made by V.A. Kovshikov. He identified three forms of the studied disorder: 1) motor (expressive); 2) sensory (impressive); sensory-motor (mixed) [5]. The difference between these forms is the location of the disorder. The focus of the disorder in sensory alalia is the Wernicke speech center, which is responsible for speech perception. In the motor form of alalia, disorders are localized in the motor center of speech - the Broca's zone, which is responsible for the movement aspect of speech [6].

Many scientists - L.S. Volkova, V.A. Kovshikov, G.V. Gurovets, V. Landau, T.B. filicheva, G.V. Chirkina, E.V. Sobotovich, and N.N. Traugott - have studied the factors that influence the occurrence of anomalies in the above-mentioned speech centers.

The most important factors are those that occur during the prenatal period of the child's development. These factors include: mother's somatic diseases during pregnancy, toxicosis, mother's infectious diseases during pregnancy, fetal hypoxia, RH-conflict between the mother and the fetus, mechanical injuries during pregnancy that lead to the threat of miscarriage, intrauterine intoxication and mother's harmful habits [7]. 
The Natal causes of the studied disorder include premature or prolonged labor, asphyxia, and birth injuries [7].

Alalia can also occur during the early development of a child, namely under 3 years old. In the post-Natal period, factors leading to disorders of the child's speech development include: meningitis, encephalitis, somatic diseases of a child, brain injuries, intoxication of a child's body with drugs or toxic substances [7].

Such scientists as R. Luhzinger, M. berry, and the Soviet scientist V.A. Kovshikov noted that intrauterine oxygen starvation (hypoxia) and asphyxia have the most significant effect on the occurrence of alalia. This theory is confirmed by the fact that insufficient oxygen supply to the brain, namely to the third layer of the cortex, leads to the disorders of associative connections that ensure the formation of higher mental functions and speech [8].

Many studies have revealed that motor alalia is the most common among other forms [9]. A broader definition of this form was given by the Soviet scientist V.A. Kovshikov. He defined expressive alalia as a language disorder that is characterized by a violation of the acquisition of expressive speech in ontogenesis, the inventory of language units and the rules of their functioning, which in the process of speech generation is manifested in the impossibility or disorder of producing grammatical, lexical and phonemic operations with complete or relative preservation of semantic and motor operations [8].

Like any other disorders, motor alalia has its own symptoms. With regard to the problem, let's consider the disorders that are noted in the lexical category of speech in older preschool children with motor alalia.

Children of the studied group have a significant discrepancy between the size of the passive and active vocabulary, which is manifested both in everyday life and in specially created conditions. Typical errors of the passive dictionary include violations of understanding: 1) singular and plural forms; 2) forms of masculine and feminine past tense verbs; 3) auxiliary parts of speech; 4) cause-and-effect relationships [3].

The detonators words are the most easily actualized words in children with expressive alalia. It is because the formative words don't have any lexical meaning, they only have grammatical meaning. Among the detonator words, the most preserved are words with a subject meaning, and less preserved are with the meaning of actions, conditions, processes, qualities, and attributes. Large deviations occur both in the perception and actualization of words that have generalizing, abstract, and figurative meanings [10].

It is important to note that the greatest number of lexical errors in children with expressive alalia is directly connected with the word search process, and not to the meanings and concepts behind these words [11].

Defects in the use of the words in active speech cause various errors - lack, omissions, substitutions of words, the usage of blends and abnormal words [12].

To build the proper correction route, it is important to identify disorders of all speech components, including lexical one. Therefore, let's consider what vocabulary disorders are typical for children with motor alalia [8]:

- Verbal substitutions resulting from incorrect choice of semantic features of the word (for example, instead of the word "pipe", the child says "smoke", "weapon" - "gun" , etc.);

- Description of the word instead of its name (for example, the child replaces the word "light bulb" with the phrase "it is lit").

- Replacing words with onomatopoeia (for example, the word "chicken" is designated as "Ko-Ko").

- Non-verbal word designations (words are shown by actions or gestures).

- Replacement in the form of anomalous words (e.g., eyelashes - bam-bam).

- Variable name of one subject in different speech situations.

- Replacing words-actions with words-objects. 
Also, the symptom of increased inhibition of speech function can be related to the disorders of the lexical aspect of speech. It was defined by N.N. Traugott and characterized as a narrow-situational vocabulary of children with motor alalia [13].

This symptom is expressed by the fact that the actualization of words in various speech situations does not occur immediately, even those learned in the classroom. The operation of learned and practiced words is slow. This defect very often leads to the replacement of the name of the word with its active search. The result of searching for the right word is to replace it with a word of similar meaning or sound. Often a child is aware of his mistake, but still can not name the desired word correctly [13].

Thus, we can conclude that the small vocabulary that children with motor alalia have reflects objects and phenomena directly perceived by the senses, as well as their actions and qualities. All of the above points to the need for correctional speech therapy work and highquality selection of methods for the development of the lexical aspect of speech in older preschool children with motor alalia.

One of the main ones is the method described by L.R. Davidovich, which is based on combining and systematizing words according to the semantic principle (this is how the vocabulary functions in the minds of children normally). This method involves studying generalizing concepts, dividing words into different groups, adding new words to these groups, and studying group differences in words and how they are used in different speech situations [14].

Also the method of cinquain is of great importance in correcting the vocabulary of the studied group of children.

Cinquain is a five line verse form that originated in the United States in the early twentieth century. It consists of five lines and involves counting the syllables in each poem [15].

In Russia cinquain has been used for didactic purposes since 1997. Didactic synquain is based not on the counting of the syllables, but on the meaning and syntax of each line [15].

The structure of the didactic cinquain: 1) The first line. It is a theme consisting of a single word (noun or pronoun) that denotes the object or phenomenon and will be discussed in the poem. 2) The second line. It consists of two words (adjectives or participles) that describe the signs and properties of the object or phenomenon of cinquain. 3) The third line. It consists of three verbs or adverbs describing the actions of an object or phenomenon. 4) The fourth line. A whole phrase, consisting of four words, that describes the personal attitude of the author of the poem to the subject or phenomenon. 5) The fifth line. It consists of a single word that describes the essence of the object or phenomenon. It can be a synonym or a generalizing word [15].

Another method for the development of the lexical aspect of speech is theatrical activity. R.I. Zhukovskaya, N.S. Karpinskaya, L.S. Furmina, E.G. Churilova identified several stages of work for the development of the dictionary through theatrical activity: 1) The first stage is characterized by the formation of children's interest to the theatrical actions. It is done by watching small performances that are conducted by a speech therapist; 2) The second stage is the inclusion of the child in the performance. The child can use facial expressions, gestures, words, phrases. At this stage, the child learns to play the role of an actor; 3) At the third stage, children begin to interact with each other [16].

Many specialists use the method of designing and creating lapbooks to develop vocabulary and update it in children with motor alalia [4].

A lapbook is a thematic folder or a clamshell folder that contains games, diagrams, illustrations, and speech material for working out a given topic [4].

This method allows to implement the principle of an individual approach, to create the material necessary for the development of each child's vocabulary. Another advantage of the method is that it is based on visual aids and design, which directly affects not only on 
the development of the vocabulary, but also on the general development of speech, thinking, cognitive activity, motivation, motor skills, and much more.

Despite the fact that this problem has been studied by many scientists, it is impossible to determine the most effective method, because the structure of the defect is different for all children. That's why, it is necessary to systematize and combine methods, techniques and material in accordance with the characteristics of the children in this category [17].

The study of the features of the development of the lexical aspect of speech with children with motor alalia was carried out in several stages: 1) diagnostic; 2) correctional speech therapy; 3) control.

Four children of senior preschool age with a diagnosis of motor alalia were selected for the experiment. The age of these children are from 5 years 10 months to 6 years 7 months.

Methods of dictionary examination by I.A. Smirnova, L.S. Solomakha, and N.V. Serebryakova and methods of emotional vocabulary examination by I.U. Kondratenko were used for the diagnostics.

I.A. Smirnova's method consists of two blocks: 1 block - research of understanding and use of nominative vocabulary in one's own speech; 2 block - research of the state of structural aspects of semantic meanings of words [3].

The first block consists of 5 tasks: Task №1.1: the state of the nominative dictionary; Task №1.2: the state of the verb dictionary; Task №1.3: the state of the attribute dictionary; Task №1.4: the dictionary of numerals; Task №1.5: the dictionary of prepositions.

The second block consists of 3 tasks: Task №2.1: antonyms; Task №2.2: synonyms; Task №2.3: part-whole.

The method of studying the lexical side of speech by N.V. Serebryakova and L.S. Solomakha also consists of two blocks: 1 block - research of a passive dictionary, 2 block research of an active dictionary [10].

The first block: passive vocabulary research consists of 5 tasks: Task №1: understanding of the specific nouns; Task №2: Parts of subjects (understanding); Task №3: Understanding of the professions; Task №4: understanding of the verbs; Task №5: dictionary of adjectives.

The second block - research of an active dictionary consists of 7 tasks: Task №1: specific nouns; Task №2: generalizing concepts; Task №3: parts of the subject; Task №4: Professions; Task №5: Verb dictionary; Task №6: dictionary of adjectives; Task №7: Antonyms.

During the general examination of children with motor alalia, disorders in emotional and volitional development were revealed. Therefore, while examining the vocabulary of the children, the technique for the study of the emotional vocabulary I.Y. Kondratenko was used. The method consists of three stages: 1) The first stage - the definition of emotions; 2) The second stage - the use of words-emotions. 3) The third stage is displaying emotions using facial expressions.

The results of usage of the I.A. Smirnova's method showed that $90 \%$ ( 3 children) of the experimental group have a low level of the lexical aspect of speech development and $10 \%$ ( 1 child) have an average level. The results indicate that there is no significant difference in the level of development of the lexical aspect of speech in children of the experimental group. But it can be noted that the difference in data is manifested in the quality of the formation of individual units of the dictionary.

According to the results of the method of N.V. Serebryakova and L.S. Solomakha, it can be concluded that $90 \%$ (3 children) of children have a low level of vocabulary development, the average level is $10 \%$ ( 1 child) of children, and a high level among children is not detected. 
The same quantitative results of the examination of the two methods confirm the presence of specific disorders in the development of the lexical side of speech in children with motor alalia of older preschool age.

Also, using the technique of I.Y. Kondratenko, a low level of emotional vocabulary formation was revealed in children with expressive alalia [18]. Data from the emotional vocabulary survey show that children's knowledge, understanding, and use of emotional words is not formed.

These methods helped to identify not only the level of development of the lexical category of speech in children with expressive alalia, but also to highlight its features and the weakest and strongest sides.

Quantitatively and qualitatively, the passive dictionary prevails over the active dictionary. As shown by the method of N.V. Serebryakova and L.S. Solomakha, children performed tasks with relative ease, showing certain objects, as well as their qualities and actions. Tasks that were used to examine the active vocabulary were performed uncertainly by children, and sometimes speech negativism and refusal to complete the task were shown. It is important to note that low active dictionary indicators are associated with difficulty finding words. Often children replaced or incorrectly named a given item, its quality or action.

Among the active dictionary the least disturbed nominative dictionary, was most charged of subjects and objects. It is important to note the elements of the lexical system that are most disturbed in children with motor alalia. These include: relative adjectives; possessive adjectives; ordinal numbers; synonyms; antonyms; naming parts of the whole subject; dictionary of prepositions.

There were also quite significant violations in children's generalization of words related to the same lexical topic. This, in turn, confirms the fact that the semantic connections of words occurring in the brain structures are not sufficiently formed.

Research in this area has shown that the most global disorders in children with motor alalia are associated with the understanding and use of abstract concepts in their own speech, namely emotional vocabulary.

Due to the fact that children suffering from motor alalia were found to have extensive violations in the development of the lexical side of speech, we can conclude that it is necessary to develop and conduct correctional speech therapy work in this area.

The goal of the stage of correctional speech therapy work is to create a correctional process for the development of the lexical side of speech in older preschool children with motor alalia by combining existing methods.

Speech therapy work was carried out from July 2019 to March 2020, in addition, tasks for the development of the lexical category of speech were included in the daily activities of children.

The program of correctional work was developed taking into account the survey data, the study of methodological literature, as well as our own adapted methods. The proposed program includes the following areas of work: 1) development of emotional vocabulary; 2) formation of semantic connections of words.

1. The development of emotional vocabulary.

The goal of this stage is to develop an understanding and ability to use emotional words in your own speech. The need for corrective work in this area is confirmed not only by the fact that words-emotions in children with motor alalia cause the greatest difficulties, but also by the fact that most children in the experimental group were found to have violations of the emotional-volitional sphere. The development of emotional vocabulary will allow not only to form a vocabulary, but also to develop in children the skill of self-control of their own emotions and behavior.

Work in this area was carried out for 2.5 months and had the following content: 
1) Study of parts and elements of the face. The task of the stage was to prepare children to study and mimic the display of emotions and emotional states. 2) introduction of the concept of "emotions". This stage of work involves the formation of semantic connections of words, as well as training in the systematization of words related to emotional vocabulary. 3) Types and manifestations of emotions. At this stage, children get acquainted with individual emotions, learn the range of emotions, that they are divided into positive and negative. 4) Study and practice the concepts of "Joy" and "Sadness". 5) Study and practice the concepts of "Fear", "Surprise". 6) Study and practice the concept of "Anger". 7) Distinguishing the main emotions studied. 8) Study and practice the concepts of "Cunning", "Mischief". 9) Study and practice the concepts of "Thoughtfulness", "Perplexity". 10) Study and practice the concepts of "Offense". 11) The additional Distinction of the studied emotions. 12) Fixing the studied material.

To implement the work on the formation of emotional vocabulary with preschool children who have motor alalia, we have developed an adapted manual "Emotions". To consolidate the studied material in front-line classes, the method of theatrical activity was used.

The entire work was constructed using the explanatory-illustrative and game method. The use of visualization is justified by the fact that words denoting objects, phenomena, actions and signs are fixed in the minds of children with expressive alalia better if they are accompanied by images. Using the game method at the formative stage of the experiment, the principle of taking into account the leading activity of children, which creates favorable conditions for development, was implemented. The following games were used in speech therapy classes:

- "Show emotion" - the speech therapist asks the child to look at the illustrations with the image of emotions, and then select the specified emotion and repeat its name;

- "Name an emotion" - the speech therapist asks the child to look at the illustrations with the image of emotions, and then name the specified emotion;

- "Draw an emotion on your face" - the speech therapist demonstrates the emotion in the illustration or depicts it himself (it is better to combine the two methods), and then asks you to depict the proposed emotion;

- "Find two identical emotions" - in front of the child is a series of images, two of which show the same emotions (on the face of a boy and a girl), the child is asked to identify two identical emotions;

- "Collect emotion" - the child is offered an illustration with a silhouette of a person, as well as a number of images of faces that display emotions. The child's task is to create an emotion set by a speech therapist;

- "Recognize an emotion by description" - the speech therapist offers the child to look at a number of illustrations of emotions, and then choose an emotion based on its preliminary description;

- "Fairy tales" - the child needs to look at the images of fairy-tale characters and determine the emotion they represent (first on the basis of images of individual characters, then on the basis of story illustrations).

At the final stage of the work, the method of theatrical activity was used. In advance, the children received a task - to get acquainted with the content of the fairy tale "Turnip". Then, in the front lesson, the children learned to find and identify the emotions that the characters of the fairy tale showed using illustrations and leading questions. Then, using props, a "Turnip" was played, where children learned to show emotions spontaneously. Also at the final stage, the children got acquainted with the method of cinquain, which was used to complete the work on the formation of emotional vocabulary.

To improve the vocabulary of this topic, the children's emotional state was recorded in all subsequent classes. It was made using cards with images of emotions. The child was 
asked to choose and name an illustration that reflects their mood at the beginning and end of the lesson.

2. The formation of semantic relations of words.

The purpose of this work is to form semantic connections, as well as to accumulate, expand and use words related to various lexical topics in one's own speech.

Lexical topics were selected based on survey data, as well as age and individual characteristics of children. These include: "Colors", "Shapes", "Vegetables", "Fruits", "Pets", "Wild animals", "Dishes", "Furniture", "food", "Clothing", "Shoes", "Professions". Let's talk about some of the topics.

To implement this direction of the formative stage of the experiment, the developed adapted manuals and manuals were used by Teremkova N.E., Davidovich L.R. Speech therapy work was organized using various methods: explanatory and illustrative, game, cinquaines, laptops.

Despite the fact that the children knew the colors and shapes, work began in this direction. This is due to the fact that children with motor alalia have great difficulties in determining the color and shape of specific objects, as well as in the non-extensive use of adjectives in their own speech. The lexical themes "Colors "and" Shapes " Were worked out using and creating laptops. Examples of games: "Determine the color of the object", "Mosaic of geometric shapes", "Connect objects of the same shape", "Colored circles", "True/false".

The development of a dictionary on the topic of "dishes" has a different structure. Initially, a general concept and related subjects were developed. Then the items were divided into three groups: kitchen, dining and tea utensils. Each group was studied separately, to improve knowledge and effective assimilation of the material. While working on this topic, we studied: 1) generalizing concept; 2) items of tableware; 3) classification of tableware; 4) possessive pronouns; 5) materials from which dishes are made; 6) purpose of dishes; 6) care of dishes; 7) plural; 8) quantitative and ordinal numbers. Examples of games: "assistant/assistant", "say the opposite", "pick up, name, remember", "visiting grandma Fedora" [19-20].

The next topic of study was "furniture". The accumulation of vocabulary on this topic caused the greatest difficulties for children, since it consists of concepts that children do not distinguish and do replace (sofa/bed, chair/chair/stool, wardrobe/nightstand, etc.). This topic is also difficult for children, because objects are classified according to their location and purpose. At first, children were taught the names of furniture items and the General concept. At the same stage of work, the elements of furniture items were studied, as well as the materials from which they are made. Then the children studied the purpose of furniture and its location in the room. Also, when developing this topic, we studied antonyms, quantitative and ordinal numerals, polysemy of the words "legs", "handle", "back", possessive pronouns, and much more. Examples of games: "what without what?", "From what?".

The last topic of the formative stage of the experiment was "Professions". During its implementation, the following tasks were worked out: 1) generalizing concepts and professions; 2) tools used by people in a particular profession; 3) actions; 4) qualities of people in each profession; 5) possessive adjectives.

Examples of games: "guess the profession", "Pick up actions", "Tools", "Nonsense".

To secure the fixation of words, in the assimilation of the child was experiencing difficulties used the method of creating cinquains.

In order for the work to be systematic and complex, children were given homework to create cinquaines, repeat the material passed in the classroom, and create laptops at the end of each lexical topic. 
After carrying out the correction and speech therapy stage of the study on the development of the lexical side of speech in children with expressive alalia of older preschool age, a control stage of the study was implemented. The purpose of the control examination is to conduct secondary diagnostics of the vocabulary of older preschool children with motor alalia.

To obtain reliable data and comparative results at the control stage of the study, the same methods were used as at the ascertaining stage - I.A. Smirnova, L.S. Solomakhi, N.V. Serebryakova, I.U. Kondratenko.

The results of the examination of the control experiment using the method of I. A. Smirnova showed that In children of the experimental group: 1) a low level of development of the lexical side of speech was not detected, 2) the largest number of children $(90 \%-3$ children) are at an average level, 3) 10\% (1 child) has moved to a high level of vocabulary formation.

Further, the diagnostic method of L.S. Solomakha And N.V. Serebryakova was carried out, which showed that: 1) children with a low level of vocabulary development were not detected during the diagnosis; 2) 90\% (3 children) have an average level; 3) 10\% (1 child) has a high level of vocabulary formation.

The homogeneous results obtained during the two diagnostics indicate that the level of the lexical side of speech in older preschool children of the experimental group was determined reliably.

It can be noted that the level of vocabulary development of children with expressive alalia of older preschool age increased after the formative work. Secondary diagnostics showed that: 1) the low level was not detected; 2) $90 \%$ (3 children) passed to the average level; 3 ) $10 \%$ ( 1 child) have a high level.

Also, at the control stage of the study, a survey of the development of emotional vocabulary in children of the experimental group was conducted. For this purpose, the method of I.Y. Kondratenko was used. Using it, it was found that among the children of the experimental group, $0 \%$ have a low and high level and 100\% (4 children) have an average level of emotional vocabulary development.

\section{Conclusions}

Thus, correctional speech therapy work and the results of the survey helped to prove that all the difficulties that arise are due to the fact that children with motor alalia have broken semantic connections of words, as well as the search for individual concepts. Correctional speech therapy work of the formative stage of the study proved that the effective development of the lexical side of speech in children of this category is possible only if a number of conditions are met, such as:

1) conducting a comprehensive diagnosis that allows you to determine all the broken structural elements of the vocabulary of a particular child;

2) organization of correctional speech therapy work taking into account the pathogenetic principle and the principle of individual approach, as well as the results of speech therapy examination;

3) providing targeted and systematic speech therapy assistance for the development of the lexical side of speech by systematizing, combining and individualizing the methods, techniques and material used. 


\section{References}

1. E.E. Artemova, On the issue of studying alalia as dysontogenesis of speech development, Psychology and education, 18, 73-84 (2006)

2. R.I. Lalaeva, N.V. Serebryakova, Correction of General speech underdevelopment in preschool children (formation of vocabulary and grammatical structure), p. 160, (SPb.: SOYUZ, (1999)

3. O.I. Azova, Analysis of the results of the study of vocabulary in the speech of children with motor alalia, Actual problems of psychological knowledge, 39, 101-107 (2016)

4. T.B. Filicheva, G.V. Chirkina, Elimination of General speech underdevelopment in preschool children, p. 224 (Moscow: iris-press, 2008)

5. V.A. Kovshikov, Expressive alalia, p.96 (Moscow: "Institute of General humanitarian research", 2001)

6. E.M. Mastyukova, Ontogenetic approach to the defect Structure in motor alalia, Defectology, 6, 13-20 (2001)

7. G.V. Zharova, Speech and non-speech symptoms of motor alalia, Russian otorhinolaryngology, 33, 38-41 (2008)

8. V.A. Kovshikov, Expressive alalia and methods of overcoming, p. 304 (it. SPb. KARO, 2006)

9. N.E. Teremkova, Speech therapy homework for children 5-7 years old with ONR. Album1, p. 28 (M.: SYNERGY, 2003)

10. T.T. Batysheva, S.A. Suvorova, S.V. Gilenkova, Alalia characteristic features, diagnostics, Child and adolescent rehabilitation, 26, 45-49 (2016)

11. N.Yu. Andreeva, Children with motor alalia - causes, research, correction. Current trends in education and science, Collection of scientific papers on the materials of the International scientific and practical conference, 3, 9-11 (2013)

12. A.M. Gorchakova, Specifics of violations of word actualization in children with expressive alalia, Collection of scientific papers SWorld, 19, 62-67 (2011)

13. K.S. Trofimova, A.A. Kovaleva, Laptop as a means of correcting vocabulary in preschool children with motor alalia, Fundamental and applied science, 9, 49-52 (2018)

14. L.R. Davidovich, T.S. Reznichenko, Does the Child Speak poorly? Why? What to do? Correctional and pedagogical work with non-speaking children, p. 112 (M.: Izdetelstvo GNOM and D, (2001)

15. T.V. Nesterova, O.Yu. Fedosova, Possibilities of cinquain in the work on the formation of the lexical side of speech in preschool children with motor alalia, Samara scientific Bulletin, 6, 86-88 (2014)

16. L.A. Mikhailova, The use of theatrical activities in the development of vocabulary in preschool children with motor alalia, Theoretical and methodological problems of modern education, 30, 27-30 (2017)

17. E.R. Mustaeva, Individualization of the content of speech therapy in motor alalia, taking into account non-speech disorders, Siberian pedagogical journal, 11, 320-330 (2009)

18. I.Yu. Kondratenko, The main directions of speech therapy work on the formation of emotional vocabulary in children with General speech underdevelopment of older preschool age, Defectology, 3, 56-69 (2003) 
19. N.E. Teremkova, Speech therapy homework for children 5-7 years old with ONR. Album2, p. 30 (M.: SYNERGY, 2003)

20. Z.V. Arakcheeva, V.A. Kvasov, The system of correctional-logopedic work with motor alalia, Organization of an inclusive educational space: status and prospects, 17, 186-189 (2017) 